\title{
Digital Technology Shaping Teaching Practices in Higher Education
}

\author{
Monika Akbar* \\ Department of Computer Science, University of Texas at El Paso, El Paso, TX, USA
}

In their quest on being effective, educators have always experimented with the art of teaching. Teaching has evolved over centuries by adopting new approaches, methods, tools, and technologies to reach a wider audience. As technologies advance, educators should carefully use, evaluate, and adopt the changes to utilize the technologies and track their impacts. This article provides a mini review to briefly describe some of the existing technical achievements that are used in higher education along with their challenges.

Keywords: digital education, educational resources, course management, courseware, technology assessment, e-book

\section{OPEN ACCESS}

Edited by:

Leman Figen Gul,

Istanbul Technical University, Turkey

Reviewed by:

Gabriella Agrusti,

Libera Università Maria SS. Assunta,

Italy

Marco Masoni,

University of Florence, Italy

*Correspondence:

Monika Akbar

makbar@utep.edu

Specialty section:

This article was submitted to

Digital Education,

a section of the journal

Frontiers in ICT

Received: 25 June 2015 Accepted: 01 February 2016

Published: 17 February 2016

Citation:

Akbar M (2016) Digital Technology Shaping Teaching Practices in

Higher Education.

Front. ICT 3:1

doi: 10.3389/fict.2016.00001

\section{INTRODUCTION}

Educators have always experimented with the art of teaching, which has evolved over centuries by adopting new approaches, methods, tools, and technologies. We have experienced a rapid growth in science and technology in the last century that resulted in groundbreaking innovations and exciting new technologies. As always, these innovations create opportunities while posing new challenges. Pedagogical practices have been greatly affected by the advancement of science and technology in the last few decades. This article provides a mini review to briefly describe some of the existing technical achievements that are used in higher education along with their challenges. Section 2 provides an overview of how technologies helped overcome the limits of space and time in higher education. Section 3 depicts various educational resources that are impacted or introduced by digital technologies. Sections 4-6 present different aspects of education [e.g., assessment and course management system (CMS)] with a discussion of technologies shaping these areas. Section 7 concludes the article with a discussion of the emerging challenges.

\section{RESTRICTION OF LOCATION AND TIME ON HIGHER EDUCATION}

Teaching at the beginning of history required both the teachers and students be at the same location at the same time. Writing tools and print media revolutionized the spread of knowledge and ideas. Along the same time, societies started establishing formal teaching places. Classrooms were the designated location for students and teachers. However, classrooms were not the sole place for learning. Libraries gave wider access to knowledge and acted as another hub of knowledge acquisition and sharing. Higher education experienced a shift from classroom with distance learning. The idea of distance education - an education where learning materials and instructions are given to students - started forming around (Nasseh, 2009). It was known as correspondence study. Universities started taking a major role in this form of education.

The introduction of broadcasting allowed more flexibility on teaching a broader audience. Broadcasting technology shaped the idea of distance education and distance learning even more. 
Radio broadcasting license were given to educational institutes (Nasseh, 2009). Later, televised lectures were broadcasted as a mean of teaching. We also saw hybrid approaches to teaching, which included a mix of correspondence study and materials on broadcast media.

Broadcasting media helped immensely to improve the quality of communication, both in terms of the time it took to communicate and the quality of communication. However, one of the biggest roadblocks of widely adopting such channels is that they only support one-way communication. There were no real-time and effective ways of knowing how the message was received on the other end. The effectiveness of the educator in delivering the material was limited by the medium's ability. While some subjects are more suitable for formal and informal education, others such as technical or scientific studies, vocational, and training programs need more hands-on approach. Technology, although has progresses leaps and bounds, is still at its infancy in terms of modeling the real-world experience that are necessary for many disciplines that requires extensive hands-on activities. With the introduction of digital technologies, distant education is now going through another layer of transformation (Valentine, 2002; Harper et al., 2004). Universities are now offering virtual courses that can be taken online. Just as correspondence study, these classes overcome the barriers of location and time. However, these classes are significantly better than correspondence study because of the improvement we are experiencing in digital communication medium.

On the positive side, courses are available to a larger student body, resources are abundant and available in different formats, and various platforms allow the students and teachers to interact effectively. On the challenging side, virtual classrooms lack the real-world interaction between students and teachers. Courses that require teamwork can suffer from the lack of effective virtual collaborative platforms. Educators need to develop curriculum that recognizes such challenges for such classes (Grudin, 1994; Sandholtz et al., 1997). Abundance of digital learning material calls for a rigorous measure on assessing the quality of those materials. The digital nature of many resources often makes it difficult for the student and teacher to preserve or achieve the resource.

Traditional classroom-based teaching is also experiencing a shift in teaching styles due to the emergence of digital technologies. Universities are starting to offer Internet access. To support various teaching approaches, classrooms are better equipped to connect to multiple platforms (e.g., desktop, laptop, and handheld devices). Projectors have advanced from opaque projectors that used light to project notes to digital touch-sensitive devices that can connect to computers allowing educators to share their lecture notes with student. Such settings encourage most institutions to foster collaborative learning through computersupported tasks (Grudin, 1994; Stahl et al., 2006). Different platforms, such as laptops, tablets, and cell phones, are changing the scope of teaching and learning (Rossing et al., 2012). Lectures are presented out of class through the flipped class teaching method (Jennifer et al., 2006; Bergmann and Sams, 2012). Some of these teaching methods are shown to increase student-teacher interaction, have the potential to improve the quality of learning, and at times show more student engagement (Beeland, 2002; Valentine, 2002). However, it remains to be seen at what rate and how these technologies are being adopted by different teachers with different teaching styles. Comprehensive studies need to be done to assess the overall impact of digital technologies in different pedagogical practices. Longitudinal studies on the same topic would also shed light on the impact of such adoption on student engagement, retention, and learning.

\section{EDUCATIONAL RESOURCES}

While books are commonly used as educational resources, lectures play a pivotal role in teaching. Digital technologies are changing how books are published and shared. It is also changing the nature of lectures. Newer technologies are allowing educators to use animation and simulation in class. The following subsections provide brief reviews of these areas.

\section{Lectures}

Teaching has always involved communication in some forms. Higher education was no different. Classes often comprise of lectures. Lecture series on special topics published as books created a passive learning channel parallel to the classes. Such passive communication persisted with the introduction of broadcasting technologies. Ease of recording videos and editing them are pushing the boundaries of recorded lecturers. Educators are capturing their lectures during or prior to a class. Not only educators, instructional videos are being created by people who are coming from different professions. Free video hosting sites, such as YouTube and Vimeo, are helping to making these videos public. These sites allow students to view the lectures at their convenience. Students can control the pace of these lectures and watch them repeatedly. However, videos are another form of media that have own challenges. The real-time and dynamic interactions in the classrooms cannot be replicated through these videos. It often becomes difficult for educators to assess students understanding when such methods are used. Many times, such as in the Flipped classroom method, these lectures are used as supplementary material, and educators spend their time in the class on solving problems or real-world scenarios related to a topic (Brecht and Ogilby, 2008). Quality of the content also poses concern since anyone with the right tool and not necessarily the right knowledge can create and host the videos on various topics. Educators have to practice caution on utilizing third-party educational video materials. Digital resources hosted in the Web are transient in nature - they can be deleted or edited at any time, without preserving and sharing the provenance of the resource. This alone makes it difficult for educators to heavily rely on digital resources that are developed by others.

Demonstration is an integral part of higher educations in many disciplines. Digital technologies are shaping the way educators demonstrate any topic. Presentation software, such as PowerPoint, Keynote, or Prezi, is changing the way educators weave a story. However, studies show that the effectiveness of such technologies depends highly on pedagogical style (Brock and Joglekar, 2011; Virtanen et al., 2012). Additionally, advancements in visualization technologies have allowed building visual aids to effectively demonstrate new concepts. Instructors are using presentation, simulation, and animation in making their lectures expressive 
and demonstrative to reach students who better connects with visual elements (Jonassen, 2006; Tufte, 2006).

The impact of such technologies on teaching is many-fold. On the positive side, these materials are re-usable, shareable, can be animated, and allow the teacher to spend more time interacting with students. On the other hand, it takes time to prepare such material, and educators need technical support in preparing and using them. Such materials may increase the pace of the class making it difficult for less prepared students to cope with the class. Research confirms that when compared to traditional lectures, the usage of such software provides students with positive class experience, though the grades are not likely to be changed significantly (Jennifer et al., 2006; Harris, 2011).

\section{Books}

Digital technologies are starting to supplement or replace traditional paper-based book. Many printed books now have electronic versions, which are known as e-books (electronic books). Portability of e-books is one of their biggest advantages. Compared to paper-based books, e-books cost less, can contain interactive animation and simulation to describe concepts, can have integrated assessments, and are often customizable. E-books are being published by publishers as well as groups and individuals. Hence, quality of e-books needs to be assessed properly to help educators make informed decisions on proper e-book for a class.

In classrooms, educators spend significant time explaining new concepts. The dynamic properties of many e-books (e.g., animation and simulation) help educators convey the same information without spending significant time and effort on presenting the topics during class. However, we should keep in consideration that while some students are good at responding to visual cues, others respond better to auditory instructions. Interactive digital books only add another layer to the activity to support learning. Interactive material is not necessarily quality material. The overall quality of the textbook has to reach certain standard in order to be effective and useful.

Some of these e-books allow educators to view student activities in the book (e.g., exercise completion and example viewing) (Shaffer et al., 2011; Edgcomb et al., 2014). Knowing if students spent enough time on a topic allows educators to better evaluate student performance as well as gauge the level of student engagement. Many of the e-books lack a robust assessment system. Activities or exercises require exact answer to be considered as a correct response. An extra space or comma can make the response mark as incorrect (Pulman and Sukkarieh, 2005). This can cause student frustrations. Students also show a preference on permanence and resale values, making e-books, at times, less desirable than print copies.

\section{Visualization, Animation, and Simulation}

Visualization, animation, and simulations are different ways of representing abstract concepts in an interactive way. Educators, across disciplines, use these techniques (Linn, 2003; Falvo, 2008). Visualization can be static and dynamic. Static visualizations often include images, figures, and diagrams. Dynamic visualizations show the progression of a concept along with the state changes. A number of tools are available that support the creation of a wide array of visualization (e.g., Circos and PiktoChart). Visualization and animation at times can be similar; however, when compared to visualization, animations do not support user interaction. Open-source and commercial software are helping educators to make various types of animated lectures. Simulation is an advanced version of visualization where a complex model changes its state following user inputs and pre-determined rules (Loughry et al., 2014). Simulations have been used in many areas of higher education ranging from social science to medical schools (Axelrod, 1997; Rodger et al., 2009; McGaghie et al., 2010).

\section{ASSESSMENTS}

Different systems have been developed to make assessments robust and effective. Systems, such as Socrative, ${ }^{1}$ Kahoot, ${ }^{2}$ Edmodo, ${ }^{3}$ and Nearpad, ${ }^{4}$ allow educators to share interactive lessons, engage students, and view student responses in real time. Educators can share and reuse their assessment materials. Many of these systems are not tied to any particular book and do not require extensive setup time, thus making them an ideal candidate for assessment platforms to be used in various courses. In recent years, e-books have also started integrating assessment framework within them. This allows educators to view and measure student progress within the book. While digital assessments usually allow faster grading, the challenges of this technique include standardized approach to support the generation; use, reuse, and sharing of the assessment materials across platforms; measures to ensure the integrity of the test; and ability to integrate and connect assessment resources to course objectives.

The effectiveness of digital assessments systems also needs to be analyzed. Multiple choice and true-false questions are often correctly assessed by most, if not all, of the current assessment systems. However, short answers and essay questions are comparatively more difficult to grade automatically. Researchers have worked on automatic assessment of student codes in Computer Science (Isong, 2001; Brecht and Ogilby, 2008; Edwards and Perez-Quinones, 2008). In such cases, assignments need to be specific about the requirements and detailed test cases must be designed to assess the output of the programs. All of which are time-consuming and require educators spend considerable amount of time on designing and developing assignments (Jackson and Usher, 1997; Falvo, 2008; Srikant and Aggarwal, 2014). The initial setup cost can outweigh the benefit of automated grading for smaller classes but holds promise for larger classes.

\section{COMMUNICATION AND COLLABORATION}

With teaching practices and resources going virtual, the need for effective communication between student and educators increases significantly. It is important for educators to be able to communicate with students using multiple communication channels. Virtual communication methods include email,

\footnotetext{
${ }^{1}$ http://www.socrative.com/

${ }^{2}$ https://getkahoot.com/

${ }^{3}$ https://www.edmodo.com/

${ }^{4}$ http://www.nearpod.com/home.php/
} 
tele-conference, and video-conference. These methods support one-to-one, one-to-many, and many-to-many communication. Open-source communication software, such as Skype and Google Hangouts, allow educators and students to communicate in real time. Some sites provide screen-sharing services along with video conferencing abilities (e.g., GoToMeeting ${ }^{5}$ ).

Educators also need to communicate with the class as a whole. Forums, discussion boards, and wikis are usually used as group communication methods. Courses with collaborative components are designed to encourage the communication among students. Such courses need effective communication platforms to support virtual collaboration. Collaborative platforms, such as CATME (Loughry et al., 2014), foster team learning. Question answering platforms, such as Piazza, ${ }^{6}$ are developed to help students ask question, as well as answer them. These platforms offer effective ways to engage student in and out of class. They support collaborative learning and community building. However, such platforms often require active and intense moderation to ensure that students are provided with a constructive environment that encourages exploration of concepts, they are supportive of each other, and are receiving the right response.

\section{COURSE MANAGEMENT SYSTEMS}

Course management systems, such as WetCT, Blackboard, Sakai, or Moodle, have been supporting educators in managing their classes for a while. Such systems offer an integrated platform for resource management, communication, and assessment. These systems are available either commercially or as open-source. Compared to open-source solutions, commercial CMS are often less flexible in updating their capabilities and more costly. Due to the complexity of these systems, institutions require dedicated technical staffs for the setup and maintenance of the services.

In recent years, open-source solutions are introduced to build online courseware. Educators can create an online course using EdX, ${ }^{7}$ Google course builder, ${ }^{8}$ Coursera, ${ }^{9}$ Udacity, ${ }^{10}$ etc. These systems are paving the path for movements such as massive open online courses (MOOCs) and big open online course (BOOCs). Most of such courses are free, making it easier for anyone around the world to enroll in these courses, attend them online, and receive certification. Some of the challenges of such movements include keeping students motivated, effective assessment of

\footnotetext{
${ }^{5}$ http://www.joingotomeeting.com/

${ }^{6}$ https://piazza.com/

${ }^{7}$ https://www.edx.org/

${ }^{8}$ https://code.google.com/p/course-builder/

${ }^{9} \mathrm{https} / / /$ www.coursera.org/

${ }^{10} \mathrm{https} / / /$ www.udacity.com/
}

\section{REFERENCES}

Axelrod, R. (1997). "Advancing the art of simulation in the social sciences," in Simulating Social Phenomena, eds R. Conte, R. Hegselmann, and P. Terna (Berlin: Springer), 21-40.

Beeland, W. D. Jr. (2002). "Student engagement, visual learning and technology: can interactive whiteboards help," in Annual Conference of the students, and creating and managing productive collaborative environment (Zheng et al., 2015). There is also the challenge for students to become familiar with multiple systems as different instructors may use different systems.

\section{CONCLUSION}

As technologies advance, pedagogical practices should carefully evolve to adopt the changes while keeping track of the impact of such technologies. One of the advantages of digital technologies in teaching is the ability to capture resource usage and student activities. E-books, educational videos, course materials, etc., are generating a large amount of usage data. Understanding how students interact with the technologies and identifying the impact of the use of advanced systems are critical for the development and sustainability of technology-dependent pedagogical practices. Learning analytic is an emerging research field that aims to address these questions.

Another advantage of digital technology is the ease of developing educational resources. The biggest challenges of this area are the quality of material and the permanence of such artifacts. Archiving and preserving educational resources are critical for understanding the transformation of higher education. Such preservation will also lay the path for studying the impact of these resources on student learning.

Adopting technologies in teaching has its challenges, as it can be difficult and time-consuming. It is up to the educator to decide the trade-off between investing time on technology adoption and its potential impact on student learning. The rewards for the initial time and effort given to include different digital components (e.g., e-book, assessment, and presentation) can be high if these components can be reused and show promising results on student learning. Organizations should also provide support and incentives for adopting technologies. Another challenge is to have interoperability between different technologies to support seamless integration of various digital components in a class.

While various digital technologies are emerging to support education, the educators are tasked with their adoption and impact on study. Course objectives, student demographic, and personal pedagogical philosophy and practice should guide such adoption. While technology is not the substitute for educators, it can complement various areas of teaching. Rigorous studies need to be conducted to understand the impacts of using digital technology in teaching.

\section{AUTHOR CONTRIBUTIONS}

The author confirms being the sole contributor of this work and approved it for publication.

Association of Information Technology for Teaching Education (Dublin: Trinity College).

Bergmann, J., and Sams, A. (2012). Flip your Classroom: Reach Every Student in Every Class Every Day. Washington, DC: International Society for Technology in Education, 7-17.

Brecht, H. D., and Ogilby, M. S. (2008). Enabling a comprehensive teaching strategy: video lectures. J. Inf. Technol. Educ. Innov. Prac. 7, 71-86. 
Brock, S., and Joglekar, Y. (2011). Empowering powerpoint: slides and teaching effectiveness. Interdiscip. J. Inf. Knowl. Manag. 6, 85-94.

Edgcomb, A., Vahid, F., Lysecky, R., Knoesen, A., Amirtharajah, R., and Dorf, M. L. (2014). Student Performance Improvement Using Interactive Textbooks: A ThreeUniversity Cross-Semester Analysis. Available at: http://static.cs.ucr.edu/store/ techreports/UCR-CSE-2014-10030.pdf (accessed December 7, 2015).

Edwards, S. H., and Perez-Quinones, M. A. (2008). "Web-CAT: automatically grading programming assignments," in Proceedings of the 13th Annual Conference on Innovation and Technology in Computer Science Education (ITiCSE '08) (Madrid: ACM), 328-328.

Falvo, D. A. (2008). Animations and simulations for teaching and learning molecular chemistry. Int. J. Technol. Teach. Learn. 4, 68-77.

Grudin, J. (1994). Computer-supported cooperative work: history and focus. Computer 27, 19-26. doi:10.1109/2.291294

Harper, K. C., Chen, K., and Yen, D. C. (2004). Distance learning, virtual classrooms, and teaching pedagogy in the internet environment. Technol. Soc. 26, 585-598. doi:10.1016/S0160-791X(04)00054-5

Harris, D. (2011). Presentation software: pedagogical constraints and potentials. J. Hosp. Leis. Sports Tourism Educ. 10, 72-84. doi:10.3794/johlste.101.339

Isong, J. (2001). Developing an automated program checkers. J. Comput. Sci. Coll. $16,218-224$.

Jackson, D., and Usher, M. (1997). "Grading student programs using ASSYST," in Proceedings of the Technical Symposium on Computer Science Education (SIGCSE), ed. Miller J. E. (San Jose: ACM), 335-339.

Jennifer, M. A., Eric, L. L., and James, A. S. (2006). The impact of presentation graphics on students' experience in the classroom. Comput. Educ. 47, 116-126. doi:10.1016/j.compedu.2004.09.003

Jonassen, D. H. (2006). Modeling with Technology: Mindtools for Conceptual Change. Upper Saddle River, NJ: Pearson Merrill Prentice Hall.

Linn, M. (2003). Technology and science education: starting points, research programs, and trends. Int. J. Sci. Educ. 25, 727-758. doi:10.1080/09500690305017

Loughry, M. L., Ohland, M. W., and Woehr, D. J. (2014). Assessing teamwork skills for assurance of learning using CATME team tools. J. Market. Educ. 6, 5-19. doi:10.1177/0273475313499023

McGaghie, W. C., Issenberg, S. B., Petrusa, E. R., and Scalese, R. J. (2010). A critical review of simulation-based medical education research: 2003-2009. Med. Educ. 44, 50-63. doi:10.1111/j.1365-2923.2009.03547.x

Nasseh, B. (2009). A Brief History of Distance Education. Available at: http://www. seniornet.org/edu/art/history.html (accessed December 7, 2015).

Pulman, S. G., and Sukkarieh, J. Z. (2005). "Automatic short answer marking," in Proceedings of the Second Workshop on Building Educational Applications Using NLP (EdAppsNLP 05) (Ann Arbor: Association for Computational Linguistics), 9-16.

Rodger, S. H., Wiebe, E., Lee, K. M., Morgan, C., Omar, K., and Su, J. (2009). "Increasing engagement in Automata theory with JFLAP," in Fortieth SIGCSE
Technical Symposium on Computer Science Education (Chattanooga, TN: ACM), 403-407.

Rossing, J. P., Miller, W. M., Cecil, A. K., and Stamper, S. E. (2012). iLearning: the future of higher education? Student perceptions on learning with mobile tablets. J. Scholarship Teach. Learn. 12, 1-26.

Sandholtz, J. H., Ringstaff, C., and Dwyer, D. C. (1997). Teaching with Technology: Creating Student-Centered Classrooms. New York, NY: Teachers College Press, Teachers College, Columbia University.

Shaffer, C. A., Karavirta, V., Korhonen, A., and Naps, T. L. (2011). "OpenDSA: beginning a community active-eBook project," in Proceedings of the 11th Koli Calling International Conference on Computing Education Research (Koli, Finland: ACM), 112-117.

Srikant, S., and Aggarwal, V. (2014). "A system to grade computer programming skills using machine learning," in Proceedings of the 20th ACM SIGKDD International Conference on Knowledge Discovery and Data Mining (New York: ACM), 1887-1896.

Stahl, G., Koschmann, T., and Suthers, D. (2006). "Computer-supported collaborative learning: an historical perspective," in Cambridge Handbook of the Learning Sciences, ed. Sawyer R. K. (Cambridge: Cambridge University Press), 409-426.

Tufte, E. R. (2006). The Cognitive Style of PowerPoint: Pitching Out Corrupts Within, Second Edition. Cheshire, CT: Graphics Press.

Valentine, D. (2002). Distance learning: promises, problems, and possibilities. Online J. Distance Learn. Adm. 5. Available at: http://www.westga.edu/ distance/ojdla/fall53/valentine53.html

Virtanen, P., Myllärniemi, J., and Wallander, H. (2012). "Diversifying higher education: innovative tools to facilitate different ways of learning," in Proceedings of Information Communication Technologies in Education (ICICTE) (Rhodes: ICICTE), 105-116.

Zheng, S., Rosson, M. B., Shih, P. C., and Carroll, J. M. (2015). "Understanding student motivation, behaviors and perceptions in MOOCs," in Proceedings of the 18th ACM Conference on Computer Supported Cooperative Work \& Social Computing (Vancouver, BC: ACM), 1882-1895.

Conflict of Interest Statement: The author declares that the research was conducted in the absence of any commercial or financial relationships that could be construed as a potential conflict of interest.

Copyright $\odot 2016$ Akbar. This is an open-access article distributed under the terms of the Creative Commons Attribution License (CC BY). The use, distribution or reproduction in other forums is permitted, provided the original author(s) or licensor are credited and that the original publication in this journal is cited, in accordance with accepted academic practice. No use, distribution or reproduction is permitted which does not comply with these terms. 